\title{
Intraspecific variability of nectar attracts different bats: the case of Pseudalcantarea viridiflora, a bromeliad with crepuscular anthesis
}

\author{
Pedro Adrián Aguilar-Rodríguez ${ }^{1}$ (D), Marco Tschapka ${ }^{2,3}$ (D), José G. García-Franco ${ }^{4}$ (D), Thorsten Krömer ${ }^{1}$ (D), \\ Juan Carlos López-Acosta ${ }^{1}$ and M. Cristina MacSwiney G. ${ }^{1 *}$
}

Received: November 27, 2020

Accepted: April 2, 2021

\begin{abstract}
Intraspecific variation in floral traits, such as nectar, could lead to differences in the identity and pollinator effectiveness of visitors between populations of a flowering plant. We studied the bat-pollinated bromeliad species Pseudalcantarea viridiflora to determine whether there are differences in the identity of its pollinators and in its nectar traits between two study sites located at different latitudes in Veracruz, Mexico. We studied phenology and determined the volume, concentration and quantity of dissolved sugars in the nectar at both sites. The northern $P$. viridiflora population produced nectar that was more sugar-rich, leading to pollination by a larger species, Anoura geoffroyi, whereas the southern populations were visited mainly by Glossophaga mutica, a smaller pollinator. The most abundant nectarivorous bats at each site differ in terms of their efficiency as pollinators, and we suggest that this might affect their contribution to the fitness of the bromeliad.
\end{abstract}

Keywords: Anoura, Bromeliaceae, chiropterophily, Glossophaga, Mexico, nectar traits, pollination, pollinator effectiveness

\section{Introduction}

The pollinator species of a given plant can change among sites (Boyd 2004; Lobo et al. 2012), as can the efficiency or effectiveness of pollinators (see King et al. 2013 for definitions related to this topic). All of these conditions may exert selective pressures on the phenotypic traits of the plant (Thompson 1994), including flowering phenology (Lobo et al. 2003), anthesis duration (Schlumpberger et al. 2009; Munguía-Rosas et al. 2010), floral morphology and size (Pérez-Barrales et al. 2007; Schlumpberger et al. 2009; Newman et al. 2014; Hattori et al. 2015), corolla coloration (Berardi et al. 2016), quantity of nectar (Schlumpberger et al. 2009; Brown et al. 2011; Gijbels et al. 2014) and the plant reproductive system (Eckert 2002). Populations that receive different floral visitors could present differentially affected reproductive efficiency and pollen flow between flowering individuals (i.e., Rovere et al. 2006). Moreover, in species with mainly nocturnal anthesis, some diurnal visitors may be capable of pollinating the plant at one site but not at another (Fleming et al. 1996; Schlumpberger et al. 2009; Aguilar-Rodríguez et al. 2016), highlighting the need to evaluate the role of diurnal vs. nocturnal floral visitors as pollinators.

Zoophilous flowering plants are typically pollinated by a subset of pollinators from the same functional group that share flower visitation behavior, morphological traits and pollination probability (i.e., perching birds, hovering

1 Centro de Investigaciones Tropicales, Universidad Veracruzana, 91000, Xalapa, Veracruz, Mexico

2 Institute of Evolutionary Ecology and Conservation Genomics, University of Ulm, D 89069, Ulm, Germany

3 Smithsonian Tropical Research Institute, 0843-03092 Balboa Ancón, Panamá, República de Panamá

4 Red de Ecología Funcional, Instituto de Ecología, 91070, Xalapa, Veracruz, Mexico

*Corresponding author: cmacswiney@uv.mx 
birds, long-tongued flies or bees, nectarivorous hovering bats, etc.), rather than by a particular species (Fenster et al. 2004; Ashworth et al. 2015). However, members of the same functional group can differ in terms of their efficiency as pollinators between plant species (Javorek et al. 2002; Tschapka 2003; Brown et al. 2011; Watts et al. 2011; Rocca \& Sazima 2013; Rogers et al. 2013; Stewart \& Dudash 2017b), probably due to ethological differences (floral constancy, number of visits performed, search time and handling time at the flowers, temporal variation of visits, pollen transfer efficiency, grooming behavior; Fishbein \& Venable 1996; Dafni et al. 2005; Fumero-Cabán \& Meléndez-Ackerman 2007; Hoehn et al. 2008; Willmer 2011), or as a result of the morphological fit between the body of the pollinator and the arrangement of floral parts (i.e. Solís-Montero \& VallejoMarín 2017). These "pollinator landscapes" impose selective pressures that may dictate floral ecotypes (Newman et al. 2014), in which floral traits and pollinator characteristics would match locally, therefore influencing pollination outcome (Willcox et al. 2017). For example, the presence or absence of the putative pollinator -in addition to other environmental factors- may correspond to geographic variation in the reproduction of plant species (Fleming et al. 1998; Quesada et al. 2004; Munguía-Rosas et al. 2010) via processes such as differential pollen limitation among populations through pollinator activity/abundance (Cosacov et al. 2008; Fernández et al. 2012).

The family Bromeliaceae comprises about 3700 species of 79 genera (Butcher \& Gouda et al. 2021), with half of the species epiphytic in habit (Zotz 2013). In this family, pollination mainly occurs through visits by the hummingbird (Kessler \& Krömer 2000; Krömer et al. 2006; Kessler et al. 2020). However, the plants of some genera, especially those of the subfamily Tillandsioideae (e.g., Guzmania, Tillandsia and Vriesea), have evolved diverse floral characteristics that attract different pollinator groups such as insects, birds and bats (Benzing 2000; Kessler \& Krömer 2000; Givnish et al. 2014; Aguilar-Rodríguez et al. 2016).

Within the bromeliads, bat pollination has been recorded in more than 40 species of 10 genera (Aguilar-Rodríguez et al. 2019a). The characteristics shared with other batpollinated plants include crepuscular/nocturnal anthesis, pale coloration of the petals, abundant, diluted (often $<20 \%$ ) and hexose-rich nectar, with a floral scent containing sulfurous compounds (Bestmann et al. 1997; Baker et al. 1998; Tschapka \& von Helversen 2007; Krömer et al. 2008). Information about the existence of geographic variation in the pollinator fauna of bromeliads is scarce. However, Sazima et al. (1999) described Vriesea gigantea Gaudich. as chiropterophilous, while Paggi et al. (2015) described the same species, at another Atlantic forest site in Brazil, as having diurnal anthesis and observed pollination by hummingbirds and bees.

Nectar production can consume up to $37 \%$ of the daily product of photosynthesis (Southwick 1984) and nectar production patterns are therefore considered to be under strong selective pressure (Heil 2011; Willmer 2011). In particular, members of Bromeliaceae expend large amounts of organic and inorganic compounds in their nectar (Göttlinger et al. 2019) and some species have developed adaptations in order to reduce nectar secretion following pollination (e.g., once pollen is removed and/or deposited; Ordano \& Ornelas 2004). Bats are energetically expensive pollinators for the plants, due to their large size (compared to other pollinators) and high metabolism (von Helversen \& Reyer 1984). Nectarivorous bats must obtain at least 5 $\mu \mathrm{l}$ of nectar of $20 \%$ sugar concentration from each flower just to recover the metabolic energy invested in the visit (Nassar et al. 1997). Since nectar is the main reward offered by the bromeliads to the pollinators (Benzing 2000), we hypothesize that it could be the floral trait most likely to reflect any differences in the energetic preference of the pollinators in a given population.

The genus Pseudalcantarea comprises three species: P. grandis, P. macropetala and P. viridiflora (Barfuss et al. 2016). These species have helicoiform corollas formed by strap-shaped, twisted petals of pale colors, with stamens and style extending beyond the petals (Beaman \& Judd 1996; Krömer et al. 2012). They produce hexose-rich nectar, suggesting pollination by bats (Krömer et al. 2008). In this genus, pollination by bats has been reported previously in P. macropetala (Aguilar-Rodríguez et al. 2014) and in $P$. viridiflora (Aguilar-Rodríguez et al. 2019b), while preliminary information pertaining to $P$. grandis suggests that it is also a chiropterophilous species (P. A. Aguilar-Rodríguez unpublished data).

In this paper, we examined pollination in the epiphytic species $P$. viridiflora in order to determine whether there are differences in the identity or importance of its main pollinators (bats) between two study sites with tropical montane cloud forest (TMCF) vegetation in the central and southeastern region of Veracruz state, in Mexico. These two sites present different richness in the nectarivorous bat species that could serve as potential pollinators of this bromeliad (Sosa et al. 2008; Coates et al. 2017). We hypothesized that the bats serve as the only pollinators of $P$. viridiflora at both sites, but that a greater number of bat species will fulfill this role at the southeastern locality with the highest species richness.

\section{Materials and methods}

\section{Study area}

The first study site is located in the central region of Veracruz state, at Rancho Viejo (19 31'28.99" N, 96 $59^{\prime} 3.99^{\prime \prime}$ W, $1480 \mathrm{~m}$ a.s.1.), in the Tlalnelhuayocan municipality (Fig. S1 in supplementary material). The climate is temperate-humid, with an annual mean 
temperature of $14^{\circ} \mathrm{C}$ and an annual precipitation of 1650 $\mathrm{mm}$, with a drier period between November and April (Muñiz-Castro et al. 2006). The natural vegetation is TMCF, which is composed of trees such as Quercus L. spp. (Fagaceae), Liquidambar styraciflua L. (Hamamelidaceae) and Clethra mexicana DC. (Clethraceae), as well as shrubs, hemiepiphytes and epiphytes (Zamora \& Castillo-Campos 1997; Toledo-Aceves et al. 2014). The site is a fragment of secondary forest on private property close to a river, where individuals of $P$. viridiflora are found together with other bromeliads, such as T. multicaulis Steud. and P. macropetala. In the study area, 26 species of bats are reported, three of them nectarivorous (Sosa et al. 2008).

We compared the data obtained in the first site (Rancho Viejo) with the information collected previously in a second locality (hereafter, Los Tuxtlas; Aguilar-Rodríguez et al. 2019b). This second study site is located in the southeastern region of the state, in the ejido of Adolfo Ruiz Cortines $\left(18^{\circ} 32^{\prime} 3.55^{\prime \prime} \mathrm{N}, 95^{\circ} 8^{\prime} 18.54^{\prime \prime} \mathrm{W}, 1030 \mathrm{~m}\right.$ a.s.l.; Fig. S1 in supplementary material), in the municipality of San Andrés Tuxtla, on the southeastern slope of the volcano San Martín Tuxtla, which forms part of the Los Tuxtlas Biosphere Reserve. Elevation of the study area ranges between 1050$1100 \mathrm{~m}$ a.s.l. The climate is temperate and humid, with an annual mean temperature of $18{ }^{\circ} \mathrm{C}$ and $40 \mathrm{~mm}$ of average precipitation per month, or $4000 \mathrm{~mm}$ per year (Soto 2004), and a drier season between March and May. The vegetation is composed of remnants of TMCF, derived secondary forests and pastures (Castillo-Campos \& Laborde 2004). The most common tree genera are Carpinus, Ulmus, and Quercus, whereas the understorey is characterized by Chamaedorea palms, (tree) ferns and epiphytes (Krömer et al. 2013). The floral observations were conducted in a fragment of secondary forest $\left(18^{\circ} 32^{\prime} 3.55^{\prime \prime} \mathrm{N}, 95^{\circ} 8^{\prime} 18.54^{\prime \prime} \mathrm{W}, 1030 \mathrm{~m}\right.$ a.s.l.; Fig. S1 in supplementary material) in which Saurauia scabrida (Actinidiaceae) predominates. This fragment connects with a larger TMCF remnant, in which individuals of $P$. viridiflora occur mostly solitary at heights of between 1.50 and $5 \mathrm{~m}$. In the Los Tuxtlas region, at least 65 bat species are reported, six of them as nectarivorous (Coates et al. 2017).

We selected these sites because both have similar altitudes, remnant trees of TMCF, and had enough individuals of $P$. viridiflora (over 100 individuals per hectare at both sites) to perform the pollination experiments and record pollinator's visits (over 100 individuals per hectare at both sites). Additionally, they offered security and accessibility to carry out the experiments in situ.

\section{Study species}

Pseudalcantarea viridiflora is an epiphytic bromeliad that forms a tank of almost $40 \mathrm{~cm}$ in diameter. Its green leaves are $25-50 \mathrm{~cm}$ in length. Its inflorescence is simple and $45-50 \mathrm{~cm}$ in length and $c a .1 \mathrm{~cm}$ in width. The flowers are actinomorphic, with a helicoiform corolla. The subsessile flower petals are light green or cream, strap-shaped and twisted, of $9 \mathrm{~cm}$ in length and $1 \mathrm{~cm}$ in width (Fig. 1). Stamen length exceeds that of the petals. The plant develops a fusiform fruit capsule of $c a .6 \mathrm{~cm}$ in length and $1 \mathrm{~cm}$ in width that contains seeds adapted to wind dispersal (Krömer et al. 2012). Pseudalcantarea viridiflora is distributed in Mexico, Guatemala, Honduras and Nicaragua (Espejo-Serna et al. 2005). This species, at least in the south of Veracruz state, is pollinated by nectarivorous bats (Aguilar-Rodríguez et al. 2019b). Plants used in this study were collected with the permission of the Secretaría del Medio Ambiente y Recursos Naturales (permit No. 02405/14 granted to MCMG). Voucher specimens of P. viridiflora collected at both study sites, Rancho Viejo (PAAR 10) and Los Tuxtlas (PAAR 9), were deposited at the herbarium XAL of the Instituto de Ecología, A.C. in Xalapa, Veracruz.

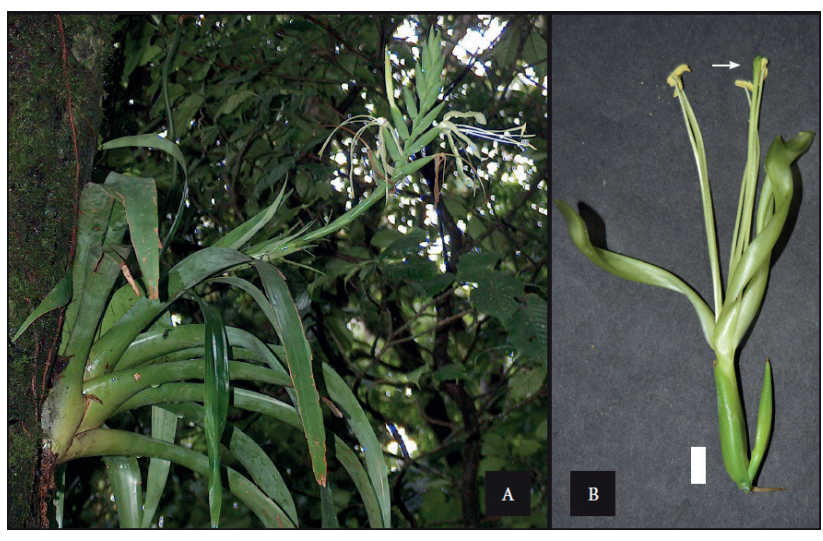

Figure 1. A) Flowering individual of Pseudalcantarea viridiflora in the TMCF of the San Martín Tuxtla volcano. B) Flower of $P$. viridiflora. The arrow indicates the stigma. White bar $=1 \mathrm{~cm}$. Photographs: A, Thorsten Krömer; B, Pedro A. Aguilar-Rodríguez.

\section{Anthesis and flowering}

We conducted the fieldwork during the peak of the $P$. viridiflora flowering period, in October 2015 at Rancho Viejo, and between the end of August and beginning of September 2014 at Los Tuxtlas (for the latter, see Aguilar-Rodríguez et al. 2019b). At both sites, we translocated specimens to accessible tree trunks and individually marked them to facilitate a continuous monitoring of the floral buds until fructification (Ollerton \& Dafni 2005). Beginning of anthesis was considered as the moment at which the petals opened to reveal the reproductive organs of the flower, while senescence was considered to have occurred when the floral parts lost turgidity and stigmatic receptivity ceased (Aguilar-Rodríguez et al. 2014). We estimated the period of stigmatic receptivity by submerging stigmas in hydrogen peroxide $\left(\mathrm{H}_{2} \mathrm{O}_{2}\right)$ every two hours during the whole anthesis (Martén-Rodríguez \& Fenster 2008). 


\section{Volume and concentration of nectar}

We took all the nectar measurements ex situ, by taking at least 10 specimens of each population to a roofed nursery in the city of Xalapa, Veracruz (located about $11 \mathrm{~km}$ from the Rancho Viejo site at similar elevation), to measure nectar production data. After translocation of specimens to this nursery, they were allowed to adapt to the local conditions for at least one week, during which the plants were maintained in a natural light: darkness regime and supplied with abundant water. Only after this habituation period, we started with the samples collection.

We determined the patterns of production and concentration of nectar. In order to calculate nectar volume, we used glass capillary tubes of 10 and $80 \mu \mathrm{l}$ to extract accumulated nectar from one flower every two hours in the same flower (standing crop collection), beginning two hours after initiation of anthesis, and continuing until the measured volume reached zero (Aguilar-Rodríguez et al. 2014; 2016). The sugar concentration was measured in Brix degrees using a handheld refractometer (Mod. HRT32, range: 0-32\%, weight/weight, precision: $0.2 \%$; A. Krüss Optronic, Germany), every two hours. We obtained the total volume of nectar produced per flower by summing the values of production measured across all of the two-hour periods (Tschapka \& von Helversen 2007). Later, we calculated the milligrams ( $\mathrm{mg}$ ) of dissolved sugars in the nectar using conversion tables and techniques explained by Kearns \& Inouye (1993) and the work of Galetto \& Bernardello (2005).

In bat-pollinated plant species, the nectar values at the end of the night are always extremely low in volume and concentration (e.g., Tschapka \& von Helversen 2007; von Helversen \& Winter 2003; Martén-Rodríguez \& Fenster 2008; Munguía-Rosas et al. 2010; Aguilar-Rodríguez et al. 2014; 2016), and it is doubtful whether the bats are still able to extract those low amounts of nectar volume. To get a more typical value (i.e., one that is on average experienced by the bats during their visits) and not over-represent the low values typically obtained later in the night, we only took into account the values from the $80 \%$ of the cumulative nectar production of each flower (the last $20 \%$ of extremely low production, were omitted) to obtain the mean volume, concentration, and $\mathrm{mg}$ of sugars of both populations. Later, we compared them conducting a rank-sum test (t-test) using the program SigmaPlot ver. 12 (Badashah \& Nath 2007).

\section{Breeding system}

Breeding and mating could vary among plant populations (Müller et al. 2000; Rovere et al. 2006; Whitehead et al. 2018). We determined the breeding system of $P$. viridiflora in a previous study using three manual pollination treatments (Aguilar-Rodríguez et al. 2019b). However, we repeated these treatments in the Rancho Viejo population to account for any variation. All individuals used for this purpose were excluded from visits by potential pollinators. The following treatments were conducted on $\geq 10$ flowers each, from at least 10 individuals, respectively: 1) Spontaneous self-pollination (a non-manipulated flower); 2) Xenogamy (cross-pollination with pollen from another individual); 3 ) Experimental autogamy (controlled self-pollination with pollen of the same flower). For each treatment, we calculated the fruit set (percentage of fructification based on the number of flowers that had developed fruits), assessed four to eight weeks after the experiments. Later, we compared the seed set per fruit following the different treatments. To assess any differences between fruit set and seed set within both populations, as well as any interaction with the study site, we used a GLM with a binomial distribution and a logit function using the program $\mathrm{R}$ ( $\mathrm{R}$ Development Core Team 2012). The pollination treatment was treated as a fixed effect, while fruit production (presence or absence) as a binary response variable, or seed number as a continuous response variable.

To establish whether P. viridiflora is self-compatible at Rancho Viejo, we obtained the Index of Self-Incompatibility (ISI) using the formula presented in Lloyd (1965), by dividing the ratio of seed set from the Autogamy treatment and the Xenogamy treatment (Zapata \& Arroyo 1978), where values of between 0.30 and 1.00 indicate self-compatibility (Kamke et al. 2011). This index was also obtained using the percentage of fructification (fruit-set; Raduski et al. 2012) as an independent variable in these treatments since using both measures better reflects the reproductive success of the plant at two levels of development (Martinelli 1994; Wendt et al. 2002). To determine if the bromeliads from both sites suffered from limited pollen supply, the Pollen Limitation Index (PLI) was calculated per site, as shown in Larson \& Barret (2000) and Becker et al. (2011). We used zero as the lower bound for the index and employed the fruit set values for this calculation. In this way, zero value means no limitation, and the closer the number approaches one, greater is the limitation.

\section{Capture of bats and collection of pollen}

We carried out mist net sampling to identify the bat species that may potentially pollinate $P$. viridiflora. Two mist nets (height $3 \mathrm{~m}$; length $6 \mathrm{~m}$ and $12 \mathrm{~m}$ ) were placed near flowering bromeliads (Martinelli 1994; Kaehler et al. 2005; Tschapka \& von Helversen 2007) or at sites serving as flight paths for bats, such as corridors, roads or openings in the vegetation (Wilson et al. 1996). Netting ceased after two hours of no captures (Santos-Moreno et al. 2010) and we avoided netting around full moon, since the activity period of the bats is shorter ("lunar phobia"; Morrison 1978). The nets were moved at least every second night of sampling to minimize learned mist-net avoidance (Marques et al. 2013). Sampling effort was measured as suggested by Straube \& Biaconi (2002). At minimum, we sampled for three hours per night at each site, starting just after dusk. For logistic and climatic reasons, the sampling effort differed in the two 
sites, at Rancho Viejo, the effort was $1014 \mathrm{~m}^{2} / \mathrm{h} /$ net, while in Los Tuxtlas this value was $19469 \mathrm{~m}^{2} / \mathrm{h} / \mathrm{net}$.

Using the field guides of Medellín et al. (2008) and Reid (2009), we identified the captured bats, following the classifications of Simmons (2005), Cirranello et al. (2016) and Calahorra-Oliart et al. (2021). We examined the captured individuals for the presence of pollen on the fur (Caballero-Martínez et al. 2009) to corroborate that these bats were visiting and transporting the pollen of $P$. viridiflora. To do this, we collected pollen with a paintbrush moistened with alcohol (Aguilar-Rodríguez et al. 2014; 2016). The pollen grains were kept with the bristles of the brush in plastic vials with at least $1.5 \mathrm{~mL}$ of $70 \%$ ethanol (Voigt et al. 2009). Pollen samples were taken from the anthers of three individuals of P. viridiflora and kept in plastic vials with $70 \%$ ethanol for comparison (size, shape, ornamentation) with the samples taken from the bat fur (Herrera \& Martínez-del-Río 1998; Muchhala \& Jarrín-V. 2002) using a microscope at $100 x$ and $400 x$ (Zeiss, Germany, Model: 426126). Determining where and approximately in what quantity are pollen grains of $P$. viridiflora transported by each bat species (which differ in body size), would help us to analyze the results of pollen occurrence (see below) and determine the efficiency of these species as pollinators.

We determined the occurrence of pollen-based on a criterion of presence/absence (Voigt et al. 2009). Each plastic vial was agitated to suspend the pollen grains and six drops were extracted and analyzed under the microscope. In each drop, we quantified the grains present using the "scanning" technique (sensu Caballero-Martínez et al. 2009), to avoid repeated quantification of the same element (Wendt et al. 2002). Then, we calculated the frequency of occurrence (Muchhala \& Jarrín-V. 2002) of the bromeliad pollen morphotype (Silva et al. 2016; Souza et al. 2017), qualifying each sample as positive on the encounter of at least three pollen grains (Heithaus et al. 1975) in each microscope field. Finally, the positive samples were summed, and we calculated the percentage relative to the total pollen grains from that bat species using all individuals captured (Caballero-Martínez et al. 2009).

\section{Observations and efficiency of floral visitors}

We recorded the nocturnal visitors, while the diurnal visitors were directly observed (Tschapka \& von Helversen 2007; Schmid et al. 2011b), in October 2015 at Rancho Viejo and between August and September 2014 at Los Tuxtlas (see Aguilar-Rodríguez et al. 2019b). The nocturnal recordings were made with a camera with night-vision capability (DCR-SR65 Sony Corporation, Japan) and an infrared light (HVL-HILR Sony Corporation, Japan), which was installed on a tripod at a $1 \mathrm{~m}$ distance from the subject flower. Recordings started at dusk and lasted 3-3.5 hours, which covers the peak of activity of phyllostomid bats (Quesada et al. 2003). We inferred the identity of the species of bats by considering their relative size, visible morphological traits, and behavior demonstrated during the visit and the presumably occurring bat species in the study zone, based on the literature (Medellín et al. 2008). Diurnal observations were made in the morning and in the late afternoon and lasted for two hours on each occasion. Observations started in the morning, 30 minutes after dawn, and lasted in the evening until just before dusk. A single observer monitored the plants at a distance of 2-3 meters.

A total of 47 and 32 hours of nocturnal recordings were made in flowers of P. viridiflora at the Rancho Viejo and Los Tuxtlas sites, respectively ( $n=15$ flowers, 7 individuals at Rancho Viejo; $n=13$ flowers, 7 individuals at Los Tuxtlas). At Rancho Viejo, recording lasted from 19:00 h to 01:30 $\mathrm{h}$. At Los Tuxtlas recording began at 19:00 $\mathrm{h}$ and finished at between 22:00 $\mathrm{h}$ and 22:30 $\mathrm{h}$ due to climatic conditions (i.e., frequent rains later at night). A total of 12 hours of diurnal observation was carried out at Rancho Viejo, and eight hours at Los Tuxtlas ( $n=13$ flowers of 9 individuals, and 16 flowers of 7 individuals, respectively). This was conducted between $07: 00 \mathrm{~h}$ and 11:00 $\mathrm{h}$, and between $17: 30$ $\mathrm{h}$ and 18:40 h, respectively.

Due to the helicoiform shape of the corolla, all animals that made contact with the base of the petals and the aperture of the calyx were classified as floral visitors, but only the visitors that made contact with the reproductive organs of the flower were considered pollinators, regarding their consumption of nectar, pollen or neither. The data recorded included a) the frequency of visits: percentage of visits, in relation to the total number of visits made by this visitor (Schmid et al. 2011a), b) the frequency of visits per flower and per hour (Fleming et al. 1996), c) the number of visits in which the visitors possibly pollinated the flower and d) the behavior of each visitor. The duration of the visit was defined as the length of time for which the mouth-parts of the pollinator remained within the corolla (Muchhala 2006).

The efficiency of the floral visitors was determined through the exclusion of different floral visitors in the field (Wendt et al. 2001; Aguilar-Rodríguez et al. 2014; 2016; 2019b), conducted on 10-20 flowers per treatment. We used mainly the concept of the efficiency presented in Montalvo and Ackerman (1986) and Dafni et al. (1987), the percentage of fruit and seed set attributed to a specific activity period of different pollinators, as well as the observation of visitor behavior during the visit to the flowers. As preliminary observations (Aguilar-Rodríguez et al. 2019b) showed that diurnal visitors did not make any contact with the reproductive parts of the flowers and that these visitors were scarce, the following treatments were conducted in both populations: 1) Nocturnal Exposure (NE), in which the stigma of the flower was exposed during the night, but covered with a plastic tube $(c a .3 \times 0.5 \mathrm{~cm})$ held with cotton during the day, held with cotton so that the flower could only be pollinated by nocturnal visitors; 2) Emasculated 
Nocturnal Exposure (ENE), which was conducted as with the previous treatment, but with the removal of the anthers (previously to anthesis to prevent self-pollination); this treatment prevents self-pollination and sires seeds only by nocturnal floral visitors (most likely bats). Finally, in a 3) Control treatment, flowers were constantly exposed to pollinators. From each treatment, we obtained the fruit set, which was compared in a similar manner to the results of the treatments for determining the breeding system.

To compare the relative pollination efficiency of the different visitors of $P$. viridiflora, the procedure described by Fleming et al. (1996) was adopted. In this calculation, the fruit set of the treatment ENE was divided by the fruit set of the control treatment, which in turn, was divided by the rate of visits/flower/hour of the pollinator of each population. In this estimate, a pollinator will score a higher effectiveness value when a lower number of visits is sufficient to reach a similar percentage of fructification as that obtained in the control treatment (Fleming et al. 1996). We used the ENE treatment in this calculation because P. viridiflora opens its flower with pollen unless we emasculate it.

\section{Results}

\section{Anthesis and flowering}

At Rancho Viejo, P. viridiflora flowered from the end of September until the end of November. At this site, each individual had 13 flowers (mean $\pm S D$ : $13.36 \pm 4.90$; range: $6-25 ; n=11$ individuals), with $1.09 \pm 0.30$ flowers opening every 1.5 days. At Los Tuxtlas, P. viridiflora flowered from July to October, although some individuals were still observed flowering in December. On average, individuals of $P$. viridiflora had 15 flowers each at this site $(15.4 \pm 3.44$; range: $10-22 ; n=10$ individuals), with $1.06 \pm 0.25$ flowers opening every 2.08 days.

Elongation of the floral bud began ca. 36 hours before anthesis. Anthesis initiated with the opening of the petals and release of the stamens and style at 18:00 $\mathrm{h}$ at Rancho Viejo ( $n=17$ flowers) and 19:00 h ( $n=37$ flower) at Los Tuxtlas. Dusk occurred at both sites between 19:00-19:15 h. Dehiscence of the anthers coincided with the beginning of anthesis, while receptivity of the stigma began between 20 and 30 minutes afterward in both populations. The stigma produced a secretion that made it look "moist" and dark green while it was receptive.

The anthers were generally free of pollen and curved by 08:00-09:00 $\mathrm{h}$ on the following morning (up to 15 hours after anthesis). Receptivity of the stigma ceased between 10:30-11:00 h, 15-17 hours after becoming receptive ( $n=10$ flowers, 6 individuals from both sites). The anthers began to open even before the petals had completely separated, which caused grains of pollen to adhere to the base of the not yet receptive stigma, before the complete opening of the flower.

\section{Nectar volume and concentration}

The Rancho Viejo site produced $179.68 \pm 156.75 \mu \mathrm{l}$ of nectar (CV: $87.24 \%$ ), with an average concentration of dissolved sugars of $10.73 \pm 2.54 \%$, or an average of $29.68 \pm 32.38 \mathrm{mg}$ of sugar per flower $(n=9$ flowers from 5 individuals). At the Los Tuxtlas site, the volume of nectar was $101.56 \pm 74.66 \mu \mathrm{l}$ (CV: $73.51 \%$ ), with an average concentration of $8.88 \pm 3.92 \%$ or an average of $12.20 \pm 11.69$ $\mathrm{mg}$ of sugar per flower ( $n=11$ flowers from 4 individuals). The average nectar volumes, and $\mathrm{mg}$ of sugars contained in the nectar were significantly different between sites (volume: $\mathrm{t}=2.33, \mathrm{df}=12.02, p=0.0037$; $\mathrm{mg}$ of sugar: $\mathrm{t}=$ $2.60, \mathrm{df}=10.51, p=0.0254$ ), while concentration was not significantly different (concentration: $\mathrm{t}=1.16, \mathrm{df}=17.91$, $p=0.258)$.

At both sites, nectar production began probably shortly after 18:00 h, but was not noticeable or measurable before 20:00 h. At this time, it reached its maximum volume and concentration (341.93 $\pm 164.94 \mu \mathrm{l}$ and $12.83 \pm 2.06 \%$ at Rancho Viejo vs. $143.86 \pm 62.66 \mu \mathrm{l}$ and $12.05 \pm 3.43 \%$ at Los Tuxtlas) and then diminished progressively throughout the night, lasting until approximately 04:00 h (Fig. 2A-B). The mg of dissolved sugars in the nectar (maximum: 55.47 $\pm 23.64 \mathrm{mg}$ and $19.00 \pm 10.91 \mathrm{mg}$ at Rancho Viejo and Los Tuxtlas, respectively) also decreased overnight.

\section{Breeding system and experiments of exclusion of visitors}

Pseudalcantarea viridiflora was found to be self-compatible at both sites (ISI=1.01 at Rancho Viejo, and ISI=0.97 at Los Tuxtlas). Only in the experimental Autogamy and Control treatments of the Rancho Viejo population did the fruit set reach $100 \%$, and no treatment at either site was below $50 \%$ (Tabs. 1, 2). The fruit set values for the Control treatments between populations were different $(U=294.5, Z=729.50$, $p=<0.001$ ), with that produced by natural pollination at the Rancho Viejo population higher than that found at Los Tuxtlas.

Differences in the fruit set and seed set within sites were found at Los Tuxtlas, where fruit set from Spontaneous Self-pollination and the ENE treatments were significantly different compared with the other treatments in the same population (GLM: Treatment Spontaneous Self-pollination: Estimate $=-0.89$, $\mathrm{SE}=0.41, \mathrm{df}=5, \mathrm{p}=0.0096$; ENE: Estimate $=-0.98$, $\mathrm{SE}=0.40, \mathrm{df}=5, \mathrm{p}=0.0048)$. The GLM showed $\mathrm{a}$ significant effect between treatment and study site also for the Autonomous Self-pollination treatment and the NE treatment (GLM: Spontaneous Self-pollination*Site: Estimate $=0.64, \mathrm{SE}=0.41, \mathrm{df}=5, \mathrm{p}=0.0342$; $\mathrm{NE}^{*}$ Site: Estimate $=0.76, \mathrm{SE}=0.439, \mathrm{df}=5, \mathrm{p}=0.0214)$. In addition, seed set was statistically significant in the 
Experimental Autogamy, ENE and NE treatments at Los Tuxtlas (GLM: Experimental Autogamy: Estimate = 391.91, $\mathrm{SE}=86.73, \mathrm{df}=5, \mathrm{p}=<0.0001$; NE: Estimate $=$ $-343.45, \mathrm{SE}=83.98, \mathrm{df}=5, \mathrm{p}=<0.0001$; ENE: Estimate $=-369.21, \mathrm{SE}=87.67, \mathrm{df}=5, \mathrm{p}=<0.0001)$, while we also found a significant effect between treatment and study site in the seed set of the treatments Spontaneous Self- pollination and the ENE treatments at Los Tuxtlas (GLM: Spontaneous-Self-pollination*Site: Estimate $=266.11$, $\mathrm{SE}=88.70, \mathrm{df}=5, \mathrm{p}=0.0031 ;$ Control$^{*}$ Site: Estimate $=-267.27, \mathrm{SE}=62.31, \mathrm{df}=5, \mathrm{p}=<0.0001)$. According to the values obtained for the Pollen Limitation Index, there is no pollen limitation in either of the study sites (PLI: Rancho Viejo = 0; Los Tuxtlas = 0.12).
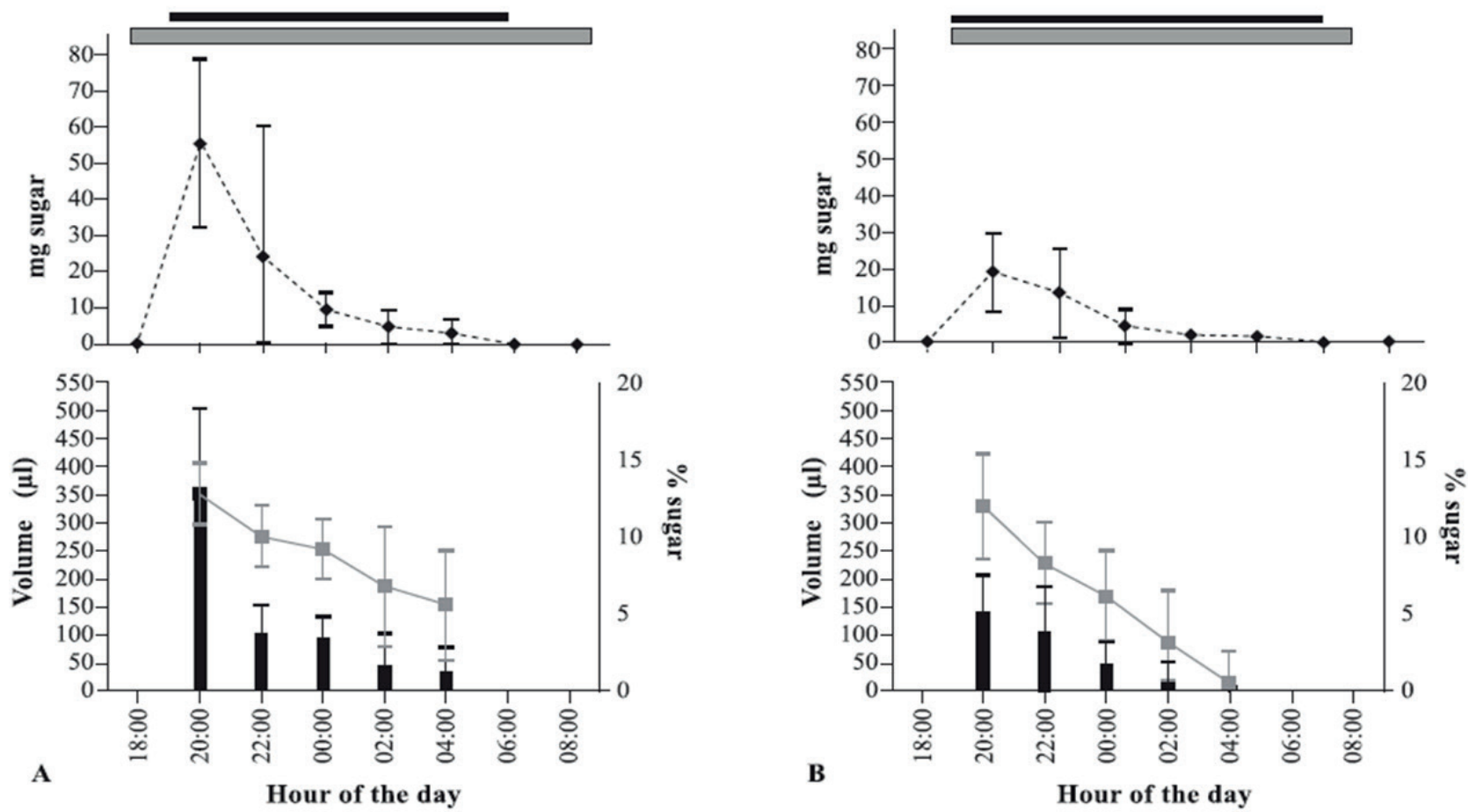

Figure 2. Production of nectar in Pseudalcantarea viridiflora at two study sites. Above: Quantity of dissolved sugar in the nectar of each population throughout anthesis. Horizontal bars in the upper part indicate the longevity of the flower (dark grey) and the nocturnal period at the study site (black line). Below: Volume (black bars) and concentration (grey line) of sugars in the nectar throughout anthesis at two study sites: A) Rancho Viejo, B) Los Tuxtlas. Vertical lines indicate the SD.

Table 1. Results of the pollination treatments conducted with P. viridiflora flowers to determine the breeding system.

\begin{tabular}{|c|c|c|c|c|c|c|}
\multirow{2}{*}{ Treatment/Site } & \multicolumn{2}{|c|}{ Flowers manipulated } & \multicolumn{2}{c|}{ \% Fruit set (N) } & \multicolumn{2}{c|}{ Seed set (means \pm SD) } \\
\cline { 2 - 7 } & Rancho Viejo & Los Tuxtlas & Rancho Viejo & Los Tuxtlas & Rancho Viejo & Los Tuxtlas \\
\hline Spontaneous self-pollination & 10 & 14 & $50.00(5)$ & $64.29(9)^{*}$ & $778.40 \pm 428.07^{\text {a }}$ & $1165.67 \pm 358.47^{\mathrm{A}}$ \\
\hline Xenogamy & 15 & 16 & $73.33(11)$ & $75.00(12)$ & $1209.18 \pm 445.77^{\mathrm{a}}$ & $967.58 \pm 354.10^{\mathrm{A}}$ \\
\hline Experimental Autogamy & 11 & 14 & $100.00(11)$ & $78.57(11)$ & $1219.27 \pm 512.94^{\mathrm{a}}$ & $930.36 \pm 485.96^{\mathrm{B}}$ \\
\hline Control & 31 & 29 & $100.00(31)$ & $65.51(19)$ & $1048.22 \pm 468.52^{\mathrm{a}}$ & $521.42 \pm 326.70^{\mathrm{A}}$ \\
\hline
\end{tabular}

Different letters within the columns of average numbers of seeds per population (lower case for Rancho Viejo, upper case for Los Tuxtlas) indicate significant differences $(\mathrm{p}<0.05)$ in the seed set or fruit set $\left(^{*}\right)$ within that population. We used 10 individuals for the Los Tuxtlas population, and 14 individuals for Rancho Viejo population.

Table 2. Results of the in situ pollination treatments conducted with P. viridiflora flowers to determine pollinator effectiveness.

\begin{tabular}{|c|c|c|c|c|c|c|}
\multirow{2}{*}{ Treatment/Site } & \multicolumn{2}{|c|}{ Flowers manipulated } & \multicolumn{2}{c|}{ \% Fruit set (N) } & \multicolumn{2}{c|}{ Seed set (means \pm SD) } \\
\cline { 2 - 7 } & Rancho Viejo & Los Tuxtlas & Rancho Viejo & Los Tuxtlas & Rancho Viejo & Los Tuxtlas \\
\hline NE & 15 & 12 & $66.66(10)$ & $83.33(10)$ & $447.4 \pm 456.585^{\mathrm{a}}$ & $217.5^{\circ} \pm 264.64^{\mathrm{A}}$ \\
\hline ENE & 15 & 10 & $60.00(9)$ & $50.00(5){ }^{*}$ & $289.67 \pm 344.66^{\mathrm{a}}$ & $508.40 \pm 366.57^{\mathrm{B}}$ \\
\hline Control & 31 & 29 & $100.00(31)$ & $65.51(19)$ & $1048.22 \pm 468.52^{\mathrm{b}}$ & $521.42 \pm 326.70^{\mathrm{C}}$ \\
\hline
\end{tabular}

Abbreviated treatment names: NE: Nocturnal exposure, ENE: Emasculated Nocturnal Exposure. Number of seeds is shown as mean \pm standard deviation. Different letters within the mean number of seeds column per population (lower case for Rancho Viejo, upper case for Los Tuxtlas), or fruit set $(*)$, indicate significant differences ( $<<0.05)$ in the number of seeds or fruits within that population. We used 10 individuals for the Los Tuxtlas population, and 14 individuals for Rancho Viejo population. 


\section{Capture of bats and collection of pollen}

At Rancho Viejo, one Anoura geoffroyi (Fig. 3A) was captured, as well as one Artibeus toltecus and five Carollia sowelli. Of these, only the A. geoffroyi individual presented pollen on the face and wing membrane. Of the pollen carried by this bat, $36.59 \%$ was identified as belonging to $P$. viridiflora (through comparison with previously collected samples).

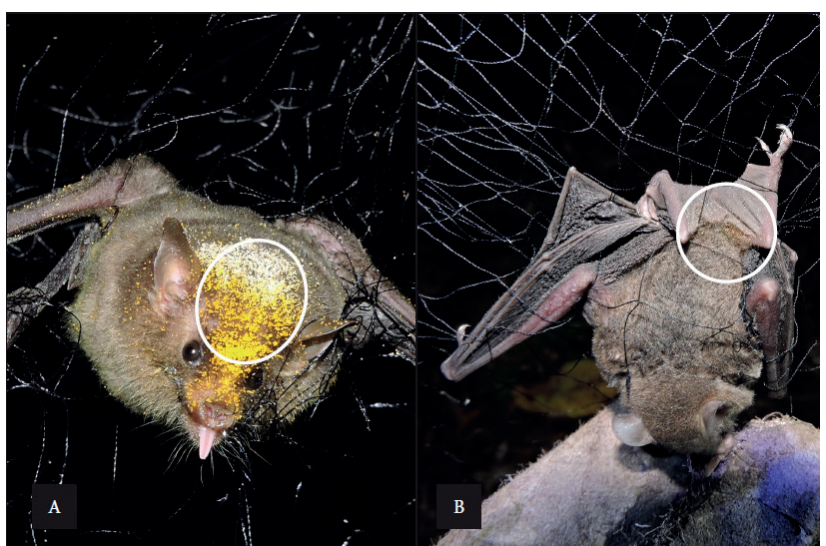

Figure 3. A) Anoura geoffroyi captured close to a Pseudalcantarea viridiflora flower at the Rancho Viejo site (with bright yellow pollen). B) Glossophaga mutica captured close to a flowering Pseudalcantarea viridiflora at Los Tuxtlas. White circles indicate where pollen was found on the body of the bat. Photographs: Pedro A. AguilarRodríguez and M. Cristina MacSwiney G.

At Los Tuxtlas, we captured 72 bats belonging to 11 species and three families during the flowering of this bromeliad: Momoopidae: Pteronotus mesoamericanus (1 individual); Phyllostomidae: Anoura geoffroyi (1), Artibeus jamaicensis (2), A. toltecus (36), Carollia sowelli (8), Desmodus rotundus (7), Glossophaga mutica (8), Hylonycteris underwoodi (1), Sturnira hondurensis (5); Vespertilionidae: Bauerus dubiaquercus (2) and Myotis nigricans (1). Pollen was found on three of the species listed above: A. geoffroyi, G. mutica (Fig. 3B) and $H$. underwoodi, all belonging to the nectarivorous Glossophagine subfamily of the Phyllostomidae. Of these, only one G. mutica and the sole individual of $H$. underwoodi were not captured close to the flowering $P$. viridiflora individuals, but along flight paths for bats. In the case of A. geoffroyi, the pollen was found mainly on the propatagium and plagiopatagium of the wing, while in G. mutica and $H$. underwoodi, the pollen was found on the uropatagium. A total of $30.77 \%$ of the pollen grains identified on G. mutica corresponded to $P$. viridiflora (mean: $12.62 \pm 18.20$ grains). Anoura geoffroyi and the $H$. underwoodi individual also carried pollen of P. viridiflora, but only 15 out of 20 grains $(75 \%)$ and two out of four grains $(50 \%)$, respectively, were counted.

\section{Efficiency and observation of floral visitors}

The recordings registered six visitor morphotypes: bats, cockroaches, spiders, moths, earwigs, and crickets (Tab. S1 in supplementary material). Considering both nocturnal and diurnal visits, 148 and 160 visits were recorded at Rancho Viejo and Los Tuxtlas, respectively. Of these visitors, only bats were considered to pollinate the bromeliad at both sites, although the frequencies differed. At Rancho Viejo, bats accounted for only $23.65 \%$ of the total number of visits, due to a high number of insect visits, while at Los Tuxtlas, bats accounted for $91.25 \%$ of all visits. At Rancho Viejo, the most frequently recorded arthropod was cricket sp. 1, with 77 visits (consuming pollen). At Los Tuxtlas, cockroaches (Blattodea) were the most frequently recorded arthropods, with three visits (thieving nectar in all of these visits).

We recorded at Rancho Viejo a total of 35 bat visits to P. viridiflora flowers, at a rate of 0.050 visits/flower/hour. At Los Tuxtlas, there were 146 visits, or 0.351 visits/flower/ hour. Visits at Rancho Viejo lasted $0.46 \pm 0.18 \mathrm{~s}$ ( $n=10$ visits selected at random, range: $0.23-0.73 \mathrm{~s}$ ), while this was 1.12 $\pm 0.33 \mathrm{~s}$ at Los Tuxtlas ( $n=10$ visits, range: $0.50-1.40 \mathrm{~s}$ ). Of the total number of visits by bats, the behavior of the animals indicated a possible pollination on 32 occasions at Rancho Viejo (91.43\% of the total number of bat visits; Fig. 4A, Video S1 in supplementary material) and on 100 occasions at Los Tuxtlas (68.49\%; Fig. 4B-C, Video S2 in supplementary material). Of these 100 visits at the latter site, the bats hovered in front of the flower on most of the occasions, apart from 11 visits, where these were "perching" on the flower while accessing the nectar. Most of the bat visits at Los Tuxtlas, legitimate or illegitimate (with no contact with reproductive structures), occurred between 19:30 $\mathrm{h}$ and 21:00 $\mathrm{h}$, with a peak between 20:00 $\mathrm{h}$ and 20:30 h. At Rancho Viejo, the bats recorded visiting P. viridiflora did so mainly around 21:00 h, by hovering in each occasion, while no "perching" behavior was observed.

Based on this foraging mode, the size of the bat (relative to the size of the flowers) the observable morphological characteristics (e.g., presence or absence of uropatagium; Fig. 3A-B) and the species captured at the sites, it is most likely that the bats recorded at Rancho Viejo belonged to the species Anoura geoffroyi, while at Los Tuxtlas these were either Glossophaga sp. or H. underwoodi.

The visits at Los Tuxtlas in which, presumably G. mutica or $H$. underwoodi perched at the flower to drink its nectar, occurred after the bats arrived and started to hover by the flowers. In these visits, the bats grasped the floral parts (petals, bracts, stamens) with their thumb claws (Fig. 4C), introduced their snouts into the flower calyx and licked the nectar, before finally leaving the flower. This type of visit caused distinct stress to the flower, as it was observed that the stamen and style remained hanging. The calculated relative effectiveness of the visiting bats as pollinators differed between the sites. The relative effectiveness as pollinators of the bat visitors at each site varied; for the bats at Rancho Viejo, the value was 12, while for the bats at Los Tuxtlas, the value was 2.19. 


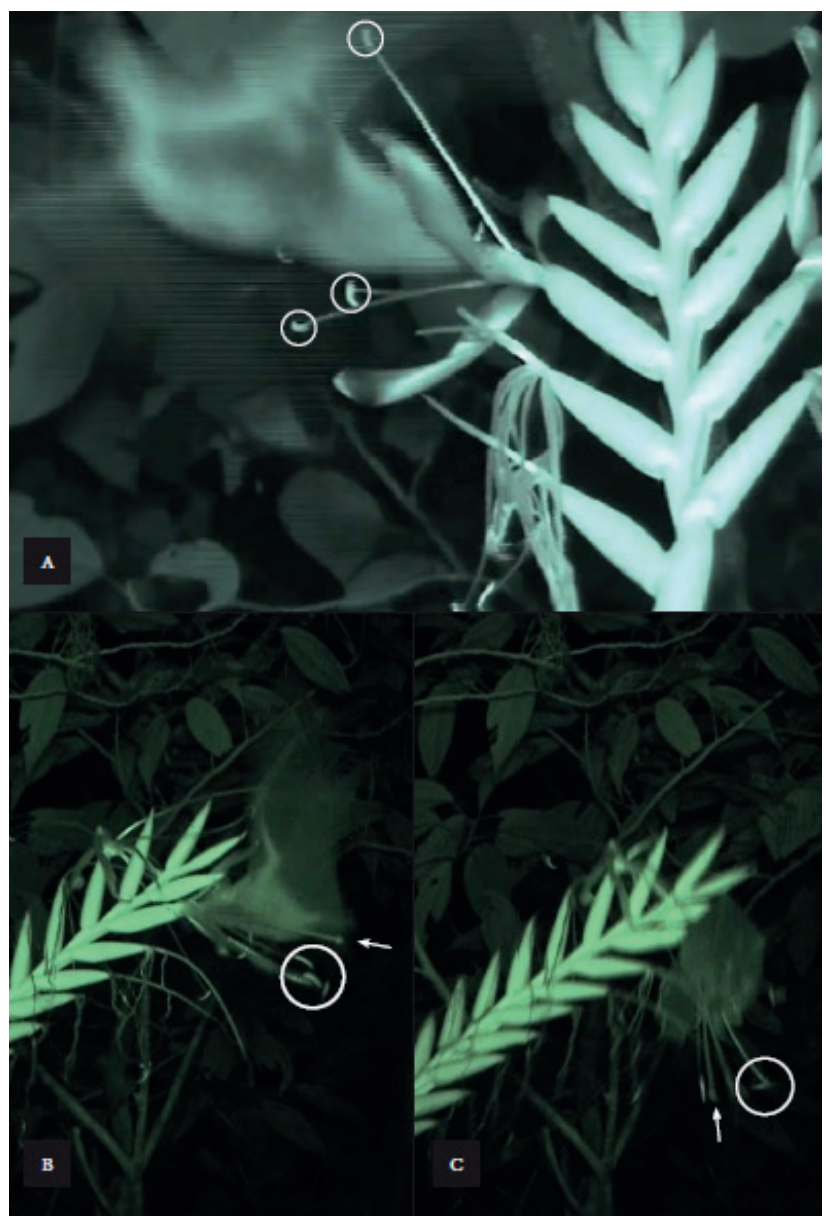

Figure 4. Bats visiting Pseudalcantarea viridiflora flowers. A) Bat, probably Anoura geoffroyi, visiting the flower at the Rancho Viejo site. B) Smaller bat, probably Glossophaga mutica, visiting the flower in flight and "perching" $\mathbf{C}$ ) on the flower. The white circle indicates the position of some anthers during the visit, and the arrow indicates the position of the stigma. Photographs: Pedro A. Aguilar-Rodríguez.

During the diurnal observation period, only arthropod visits were recorded at Los Tuxtlas, while one hummingbird species of the genus Lampornis was observed at Rancho Viejo (Tab. S1 in supplementary material). No diurnal visitor appeared to pollinate the flowers of P. viridiflora at either site, and the majority of visitors only sought the remnant nectar or pollen in the flowers.

\section{Discussion}

The results show that $P$. viridiflora is a self-compatible bromeliad capable of self-pollination at both sites, and also confirm that the species is pollinated by nectarivorous bats (as reported in Aguilar-Rodríguez et al. 2019b). Furthermore, this bromeliad therefore seems to be ecologically specialized (sensu Fenster et al. 2004) in terms of its pollinator group at either site, since it is primarily chiropterophilous, with
$>60 \%$ of the visits corresponding to bats (Cruz-Neto et al. 2015), although stigmatic receptivity and the presence of pollen on the anthers were observed during diurnal hours following initiation of anthesis.

As expected, there was variation in the bat-pollinators of P. viridiflora between the two sites, but it seems that only a subset of the available nectarivorous bat fauna are frequent visitors of this bromeliad. At Rancho Viejo, we found that $P$. viridiflora was pollinated only by $A$. geoffroyi, while at Los Tuxtlas it was pollinated by G. mutica, A. geoffroyi and possibly also $H$. underwoodi (based on the captured bats as well as analysis of the video recordings). Other potential nectarivorous bats not recorded in this study included Choeroniscus godmani for Rancho Viejo, and C. godmani, Glossophaga commissarissi and Leptonycteris yerbabuenae for Los Tuxtlas, while the two sites shared at least $A$. geoffroyi and G. mutica (Sosa et al. 2008; Coates et al. 2017). Thus, other nectarivorous species could potentially pollinate both $P$. viridiflora populations, but these may have been underrepresented due to being less tolerant to the anthropized conditions of the study sites (Reid 2009). For example, only one individual of the bat $H$. underwoodi was captured at Los Tuxtlas even after a considerable sampling effort.

Nectar is one of the most important food rewards that contain sugar and other constituents such as amino acids, phenolic compounds or alkaloids that are important for pollinators and serve to influence their preferences and behavior (Parachnowitsch et al. 2019; Ryniewicz et al. 2020). It is, however, a variable trait: in this study, differences in volume and sugar content were found in nectar traits measured between the two populations of $P$. viridiflora studied, with the highest nectar volume recorded in the Rancho Viejo population. Nectar composition in Bromeliaceae seems to be more influenced by their putative pollinator than by a phylogenetic trait (Krömer et al. 2008; Göttlinger et al. 2019). Even so, nectar composition does not remain constant in individuals of the same species cultivated at different locations (Göttlinger et al. 2019), or in those individuals cultivated in glasshouses (Canto et al. 2007). Different populations of the same flowering species present high variability in terms of sugar composition and nectar volume and concentration (Chalcoff et al. 2006; Brown et al. 2011; Noe et al. 2019). Besides, the volume and sugar concentration of nectar could be altered by endogenous factors, such as individual variability, but also by exogenous factors, such as light, temperature, humidity and others, including the actions of nectar thieves (Boose 1997; Canto et al. 2007; Heil 2011) and intra-plant variation (Hodges 1993; Biernaskie \& Cartar 2004; Herrera et al. 2006). The latter could even exceed the variations found at population level (Zywiec et al. 2012; Noe et al. 2019).

We recognize that our methods could have affected the nectar measurements obtained in the field and that our samples are relatively limited in number (in part, as a result of the scattered distribution of this bromeliad); however, 
in order to compare nectar traits in this manner in the field, we had to contend with many in situ variables. For example, it has been identified that nectar traits vary to a greater extent under field conditions than in the greenhouse, probably due to the influence of biotic (e.g., exposure to visitation, presence of yeast in nectar) or environmental (e.g., high humidity) factors (Canto et al. 2007; Chalcoff et al. 2006; Willmer 2011). Moreover, the action of bagging the flowers in the field may alter nectar volume and concentration (Wyatt et al. 1992). We tried to attenuate these environmental effects by taking ex situ measurements, but the stress associated with the translocation of the plants, as well as intra-individual variation, might still have had some impact on these measurements.

In some bromeliads, repeated floral visits increase the volume of nectar and the quantity of diluted sugar it contains (Ordano \& Ornelas 2004; Stahl et al. 2012), but their effects can also be neutral or negative (Willmer et al. 2011). The higher presence of nectar-robbers (including hummingbirds) at Rancho Viejo compared to Los Tuxtlas may have also increased the local nectar production (Lara \& Ornelas 2002). At this latter site, the higher availability of sympatric flower resources could cause that visiting nectar thieves might ignore the flowers of $P$. viridiflora. Nevertheless, it is interesting to consider that, at Rancho Viejo, where the nectar reward is greater in both volume and sugar concentration, $P$. viridiflora is pollinated by a larger pollinator, A. geoffroyi, a species with higher energetic requirements than G. mutica (Voigt 2004). Taking into account that $A$. geoffroyi is a common species at Los Tuxtlas, and that it is the main pollinator of other sympatric bromeliads in the study site (i.e., Pitcairnia recurvata, Aguilar-Rodríguez et al. 2019b), it is unclear why this species does not act as the main pollinator of $P$. viridiflora in this site. Recent studies in Mexican temperate forests show that seasonality affects the sex ratio and phenology of $A$. geoffroyi, promoting regional altitudinal migrations to favor reproduction in this species (Saldaña-Vazquez et al. 2020), which might explain its lower abundance at the time when P. viridiflora is flowering at Los Tuxtlas. However, further studies are required to explain whether differences in pollinators are directly related to the floral reward, to pollinator population migrations or are produced by specific environmental conditions.

\section{Reproductive implications due to different bat pollinators}

Bats are important long-distance pollen vectors (von Helversen \& Winter 2003; Fleming et al. 2009), transporting even more conspecific pollen from a given plant than hummingbirds (Muchhala \& Thomson 2010). Even for a self-compatible plant, a long-distance pollinator could be important for maintaining cross pollination and good progeny quality, especially in fragmented landscapes such as those of this study (Quesada et al. 2006; Aguilar et al. 2019).
Bat foraging behavior and home ranges vary among species (Ghazoul 2005). A small nectarivorous bat would need to visit fewer flowers and could, in turn, offer shorter pollen transport distances to the bromeliad (see Hmeljevski et al. 2017) than a larger bat. The home range of $G$. soricina is small (Fleming et al. 1993), with a flight distance of at least 500 $\mathrm{m}$ and up to 3-5 km (Aguiar et al. 2014). This represents a smaller area than that utilized by larger nectarivorous bats that are more mobile and can track resources over larger areas, such as Leptonycteris spp. (von Helversen \& Winter 2003). Based on its flight morphology and size, the larger A. geoffroyi could be expected to utilize a larger home range than G. mutica (Sperr et al. 2011) or H. underwoodi and could thus serve as a long-distance pollinator for the bromeliad.

Even if not statistically significant (probably because of the uneven number of treatments at both sites), it seems that when we exclude the possibility of self-pollination in the field, the fruit set and seed set both decrease. It is important to note that self-pollination, which takes place prior to exposure of the flowers to pollinators (such as in the case of $P$. viridiflora), acts to reduce the number of ovules available for conspecific pollen from another individual, but guarantees a certain number of fertilized ovules (Lloyd 1992). Such a reproductive system that ensures self-pollination, or performs it to an intermediate extent, as would seem to be the case in P. viridiflora at both sites, can be an advantageous backup-system when pollen is limited in the habitat (Kennedy \& Elle 2008).

Different bat species could affect the reproductive output of flowering plants through differences in their behavior, e.g., in the mode and frequency of visits, as well as in body mass (Tschapka 2003; Frick et al. 2013; Stewart \& Dudash 2017a). Furthermore, angiosperm species that share pollinating bats have been reported to deposit/collect pollen on various body parts of the bat, thus facilitating reproductive isolation (Muchhala \& Thomson 2012; Stewart \& Dudash 2016), although we still lack sufficient information in this regard and cannot rule out the possibility that $A$. geoffroyi and $G$. mutica/H. underwoodi might be functionally complementary to the bromeliad (Fründ et al. 2013).

It should be noted that the relatively long style of the other two self-compatible but strictly xenogamous species of Pseudalcantarea (>12 $\mathrm{mm}$ in $P$. grandis and $P$. macropetala; Krömer et al. 2012) might be of sufficient length to prevent pollination by smaller bats, such as $G$. mutica. This could broadly suggest a tendency towards evolutionary specialization in "larger" bat species and less reliance on spontaneous self-pollination for this genus. For example, A. geoffroyi is the main pollinator recorded for $P$. macropetala in a population near to the one studied here at Rancho Viejo (Aguilar-Rodríguez et al. 2014). While visiting this species, A. geoffroyi presented a similar visitation frequency ( 0.034 visits/flower/hour) as recorded for P. viridiflora at Rancho Viejo (0.050 visits/flower/hour), obtaining in both cases a PLI about zero. This contributes 
to the notion that, even if it is as frequent a pollinator as members of Glossophaga spp., this larger bat species might transport enough pollen to be an advantageous pollinator to other bigger and xenogamous bromeliads that present a poor fit between their reproductive organs and the bodies of smaller nectarivorous bats, even if the floral morphology is almost identical to that of P. viridiflora.

Pollen load was more conspicuous on the forehead fur and wings of the A. geoffroyi captured at both sites than on the uropatagium of the G. mutica captured at Los Tuxtlas (Fig. 3A-B). The stigma of $P$. viridiflora should be able to collect pollen from the body of the bat, but it is likely that pollen in the fur of A. geoffroyi (on its forehead and arms) will have a greater opportunity for deposition on the stigma than that found on the small and less hairy uropatagium of G. mutica. We acknowledge that some pollen on the wings may be lost during manipulation of the bats, even though we tried to collect it as soon as possible before releasing the bat from the net to take measurements. The percentage of bromeliad pollen carried by the bats is only a proxy for the actual proportion of the presence of the bromeliad in the bat's diet, but it is useful to understand that, in addition to $P$. viridiflora, both $A$. geoffroyi and G. mutica also visit other plant species during the flowering period of this bromeliad (see other examples in Sánchez-Casas \& Álvarez 2000; Caballero-Martínez et al. 2009; Aguilar-Rodríguez et al. 2019b).

Visits by smaller nectarivorous bats in Los Tuxtlas (either G. mutica or H. underwoodi), were longer in duration than those of $A$. geoffroyi $(1.12 \pm 0.33$ s vs. $0.46 \pm 0.18$ $s$ respectively), and the rate of visits was also higher at Los Tuxtlas than in A. geoffroyi at Rancho Viejo (0.351 vs. 0.050 visits/flower/hour). A total of $91 \%$ of the visits of A. geoffroyi were legitimate, compared to $68 \%$ of G. mutica. Relative effectiveness as a pollinator of $P$. viridiflora in both bat species differs widely, considering the rate of visits and fructification derived exclusively from the pollen transported by these pollinators. While the smaller bats at Los Tuxtlas present a higher visit rate, A. geoffroyi requires fewer visits to achieve the same reproductive success seen in the field (bearing in mind that part of this fructification is derived from the pollen of P. viridiflora itself, because of spontaneous pollination). It would be valuable to conduct ex situ experiments to assess whether either of these bats actually sires more seeds per visit. The most widely accepted method to measure effectivity in pollination ecology is comparison of per-visit fruit set among pollinator taxa (Ne'eman et al. 2010; King et al. 2013); however, this method is effective only for those plants and pollinator taxa for which a visit is necessary in order to begin fruit formation (Wang et al. 2017) and is therefore inappropriate for species with multiple ovules (Ne'eman et al. 2010). Moreover, it is methodologically complicated to accurately document per-visit effectivity in nocturnal floral visitors.
In conclusion, while both the reproductive system and pollination mode of $P$. viridiflora appear to be similar in both populations, there are some interesting differences. First, the fruit set and seed set of the treatments at Los Tuxtlas are affected by the site, possibly due to an environmental factor, which could also include those pollinators that help the flowers to reach a higher fruit and seed set such as that of the Control or Xenogamy treatments. Secondly, the nectarivorous bat species recorded as putative pollinators are of different species, which also differ in terms of their visitation behavior and size, both of which are traits that could produce a differential contribution to pollination of the bromeliad. Thirdly, we found at least an indication of differences in nectar production between sites, which could, in theory, favor the maintenance of a larger bat pollinator.

Knowledge of the natural history of a plant-animal interaction is the first step towards addressing more complex questions regarding the nature of this interaction and determining how different species could contribute to the reproduction of a plant. Pollinator size and the frequency and manner in which the pollinators undertake floral visits, could promote differences in the contributions of sympatric pollinating species to the reproductive success of the visited plants. It is also worth noting that pollinator effectiveness can change according to season (Fishbein \& Venable 1996; Rocca \& Sazima 2013; Leal et al. 2020). Further and more detailed studies should use other indicators of reproductive success (i.e., germination and vigor test in the seeds or other post-seed variables or genetic components: Valverde et al. 2019) with an ex situ experimental design, in order to assess pollinator effectiveness among members of the same pollinator guild.

\section{Acknowledgements}

We thank José Luis Libreros, Esteban Francisco Ventura, Oscar Ameca, Pedro Díaz, Emmanuel Pantoja, Zuemy Vallado, Lilia Ruiz, Hebert P. Hernández, Emmanuel Solís, Misael Nieto, Samaria Armenta, Luis Abarca, Enriqueta Velarde and the community group Los Clarines. We also thank Andrew P. Vovides and Sonia Galicia from INECOL for help in the laboratory. This work was supported through a doctoral grant to PAAR from CONACYT (No. 59406). Keith MacMillan and Erick Wild corrected the English version of the manuscript.

\section{References}

Aguiar LMS, Bernard E, Machado RB. 2014. Habitat use and movements of Glossophaga soricina and Lonchophylla dekeyseri (Chiroptera: Phyllostomidae) in a Neotropical savannah. Zoologia (Curitiba) 31: 223-229.

Aguilar R, Cristóbal-Pérez AJ, Balvino-Olvera FJ, et al. 2019. Habitat fragmentation reduces plant progeny quality: a global synthesis. Ecology Letters 22: 1163-1173. 


\section{Pedro Adrián Aguilar-Rodríguez, Marco Tschapka, José G. García-Franco, Thorsten Krömer, Juan Carlos López-Acosta and M. Cristina MacSwiney G.}

Aguilar-Rodríguez PA, Krömer T, García-Franco JG, MacSwiney GMC. 2016. From dusk till dawn: Nocturnal and diurnal pollination in the epiphyte Tillandsia heterophylla (Bromeliaceae). Plant Biology 18: 37-45.

Aguilar-Rodríguez PA, Krömer T, Tschapka M, García-Franco JG, EscobedoSarti J, MacSwiney GMC. 2019a. Bat pollination in Bromeliaceae. Plant Ecology \& Diversity 12: 1-19.

Aguilar-Rodríguez PA, MacSwiney GMC, Krömer T, García-Franco JG, Knauer A, Kessler M. 2014. First record of bat-pollination in the species-rich genus Tillandsia (Bromeliaceae). Annals of Botany 113: 1047-1055.

Aguilar-Rodríguez PA, Tschapka M, García-Franco JG, Krömer T, MacSwiney GMC. 2019b. Bromeliads going batty: pollinator partitioning among sympatric chiropterophilous Bromeliaceae. AoB Plants 11: plz014. doi: 10.1093/aobpla/plz014

Ashworth L, Aguilar R, Martén-Rodríguez S, et al. 2015. Pollination syndromes: A global pattern of convergent evolution driven by the most effective pollinator. In: Pontarotti P. (ed.) Evolutionary Biology: biodiversification from genotype to phenotype. Cham, Switzerland, Springer. p. 203-224.

Badashah SN, Nath RV. 2007. Multivariate analysis of variance. SYSTAT 12 manual-Statistics-III. San Jose, CA, USA, SYSTAT Software Inc. Technology.

Baker HG, Baker J, Hodges SA. 1998. Sugar composition of nectars and fruits consumed by birds and bats in the tropics and subtropics. Biotropica 30: 559-586.

Barfuss MHJ, Till W, Leme EMC, et al. 2016. Taxonomic revision of Bromeliaceae subfam. Tillandsioideae based on a multi-locus DNA sequence phylogeny and morphology. Phytotaxa 279: 001-097.

Beaman RS, Judd WS. 1996. Systematics of Tillandsia subgenus Pseudoalcantarea Bromeliaceae. Brittonia 48: 1-19.

Becker T, Voss N, Durkas W. 2011. Pollen limitation and inbreeding depression in an 'old rare' bumblebee-pollinated grassland herb. Plant Biology 13: 857-864.

Benzing DH. 2000. Bromeliaceae. Profile of an adaptive radiation. Cambridge, Cambridge University Press.

Berardi AE, Fields PD, Abbate JL, Taylor DR. 2016. Elevational divergence and clinal variation in floral color and leaf chemistry in Silene vulgaris. American Journal of Botany 103: 1-16.

Bestmann HJ, Winkler L, von Helversen O. 1997. Headspace analysis of volatile flower scent constituents of bat-pollinated plants. Phytochemistry 46: 1169-1172.

Biernaskie M, Cartar RV. 2004. Variation in rate of nectar production depends on floral display size: a pollinator manipulation hypothesis. Functional Ecology 18: 125-129.

Boose DL. 1997. Sources of variation in floral nectar production rate in Epilobium canum (Onagraceae): Implications for natural selection. Oecologia 110: 493-500.

Boyd AE. 2004. Breeding system of Macromeria viridiflora (Boraginaceae) and geographic variation in pollinator assemblages. American Journal of Botany 91: 1809-1813.

Brown M, Downs CT, Johnson SD. 2011. Covariation of flower traits and bird pollinator assemblages among populations of Kniphofia linearifolia (Asphodelaceae). Plant Systematics and Evolution 294: 199-206.

Butcher D, Gouda EJ. 2021. The New Bromeliad Taxon List. University Botanic Gardens, Utrecht. http://bromeliad.nl/taxonList/.14 Nov. 2021.

Caballero-Martínez LA, Rivas Manzano IV, Aguilera Gómez LI. 2009. Hábitos alimentarios de Anoura geoffroyi (Chiroptera: Phyllostomidae) en Ixtapa del Oro, Estado de México. Acta Zoológica Mexicana 25: 161-175.

Calahorra-Oliart A, Ospina-Garcés SM, León-Paniagua L. 2021. Cryptic species in Glossophaga soricina (Chiroptera: Phyllostomidae): do morphological data support molecular evidence? Journal of Mammalogy 102: 54-68.

Canto A, Pérez R, Medrano M, Castellanos MC, Herrera CM. 2007. Intraplant variation in nectar sugar composition in two Aquilegia species (Ranunculaceae): contrasting patterns under field and glasshouse conditions. Annals of Botany 99: 653-660.

Castillo-Campos G, Laborde DJ. 2004. La vegetación. In: Guevara S, Laborde DJ, Sánchez-Rios G. (eds.) Los Tuxtlas. El paisaje de la sierra. Xalapa, Mexico, Instituto de Ecología, A. C. \& European Union. p. 231-269.
Chalcoff VR, Aizen MA, Galetto L. 2006. Nectar concentration and composition of 26 species from the temperate forest of South America. Annals of Botany 97: 413-421.

Cirranello A, Simmons NB, Solari S, Baker RJ. 2016. Morphological diagnoses of higher-level phyllostomid taxa (Chiroptera: Phyllostomidae). Acta Chiropterologica 18: 39-71.

Coates R, Ramírez-Lucho I, González-Christen A. 2017. Una lista actualizada de los murciélagos de la región de Los Tuxtlas, Veracruz. Revista Mexicana de Biodiversidad 88: 349-257.

Cosacov A, Nattero J, Cocucci AA. 2008. Variation of pollinator assemblages and pollen limitation in a locally specialized system: the oil-producing Nierembergia linariifolia (Solanaceae). Annals of Botany 102: 723-734.

Cruz-Neto O, Machado IC, Galetto L, Lopes AV. 2015. The influence of nectar production and floral visitors on the female reproductive success of Inga (Fabaceae): a field experiment. Botanical Journal of the Linnean Society 177: 230-245.

Dafni A, Eisikowitch D, Ivri Y. 1987. Nectar flow and pollinator's efficiency in two co-occurring species of Capparis (Capparaceae) in Israel. Plant Systematics and Evolution 157: 181-186.

Dafni A, Kevan PG, Husband BC. 2005. Practical pollination biology. Cambridge, Canada, Enviroquest.

Eckert CG. 2002. Effect of geographical variation in pollinator fauna on the mating system of Decodon verticillatus (Lythraceae). International Journal of Plant Sciences 163: 123-132.

Espejo-Serna A, López-Ferrari AR, Ramírez-Morillo I. 2005. Bromeliaceae. Flora de Veracruz. Fascículo 136. Xalapa, Mexico, Instituto de Ecología, A. C. \& University of California.

Fenster CB, Armbruster WS, Wilson P, Dudash MR, Thomson JD. 2004. Pollination syndromes and floral specialization. Annual Review of Ecology, Evolution, and Systematics 35: 375-403.

Fernández JD, Bosch J, Nieto-Ariza B, Gómez JM. 2012. Pollen limitation in a narrow endemic plant: geographical variation and driving factors. Oecologia 170: 421-431.

Fishbein M, Venable DL. 1996. Diversity and temporal change in the effective pollinators of Asclepias tuberosa. Ecology 77: 1061-1073.

Fleming TH, Geiselman C, Kress WJ. 2009. The evolution of bat pollination: a phylogenetic perspective. Annals of Botany 104: 1017-1043.

Fleming TH, Maurice S, Hamrick J. 1998. Geographic variation in the breeding system and the evolutionary stability of trioecy in Pachycereus pringlei (Cactaceae). Evolutionary Ecology 12: 279-289.

Fleming TH, Tuttle MD, Horner MA. 1996. Pollination biology and the relative importance of nocturnal and diurnal pollinators in three species of Sonoran Desert columnar cacti. Southwest Naturalist 41: 257-269.

Fleming TH. 1993. Plant-visiting bats. American Scientist 81: 460-467.

Frick WF, Price RD, Heady III PA, Kay KM. 2013. Insectivorous bat pollinates columnar cactus more effectively per visit than specialized nectar bat. American Naturalist 181: 137-44.

Fründ J, Dormann CF, Holzschuh A, Tscharntke T. 2013. Bee diversity effects on pollination depend on functional complementarity and niche shifts. Ecology 94: 2042-2054.

Fumero-Cabán JJ, Meléndez-Ackerman EJ. 2007. Relative pollination effectiveness of floral visitors of Pitcairnia angustifolia (Bromeliaceae). American Journal of Botany 94: 419-424.

Galetto L, Bernardello G. 2005. Rewards in flowers: Nectar. In: Dafni A, Kevan PG, Husband BC. (eds.) Practical Pollination Biology. Ontario, Canada, Enviroquest Ltd Cambridge. p. 261-313.

Ghazoul J. 2005. Pollen and seed dispersal among dispersed plants. Biological Review 80: 413-443.

Gijbels P, Van den Ende W, Honnay O. 2014. Landscape scale variation in nectar amino acid and sugar composition in a Lepidoptera pollinated orchid species and its relation with fruit set. Journal of Ecology 102: 136-144.

Givnish TJ, Barfuss M, Van Ee B, et al. 2014. Adaptive radiation, correlated and contingent evolution, and net species diversification in Bromeliaceae. Molecular Phylogenetics and Evolution 71: 55-78.

Göttlinger T, Schwerdtfeger M, Tiedge K, Lohaus G. 2019. What do nectarivorous bats like? Nectar composition in Bromeliaceae with special emphasis on bat-pollinated species. Frontiers in Plant Science 10: 205. doi: 10.3389/fpls.2019.00205 


\section{Intraspecific variability of nectar attracts different bats: the case of Pseudalcantarea viridiflora, a bromeliad with crepuscular anthesis}

Hattori M, Nagano Y, Itino T. 2015. Geographic variation in flower size and flower-visitor composition of two bumblebee-pollinated, springflowering herbs, Lamium album L. var. barbatum (Lamiaceae) and Meehania urticifolia (Lamiaceae). American Journal of Political Science 6: 737-745.

Heil M. 2011. Nectar: generation, regulation and ecological functions. Trends in Plant Science 16: 191-200.

Heithaus ER, Fleming TH, Opler PA. 1975. Patterns of foraging and resource utilization in seven species of bats in a seasonal tropical community. Ecology 56: 841-854.

Herrera CM, Pérez R, Alonso C. 2006. Extreme intraplant variation in nectar sugar composition in an insect-pollinated perennial herb. American Journal of Botany 93: 575-581.

Herrera LGM, Martínez-del-Río C. 1998. Pollen digestion by New World bats: effects of processing time and feeding habits. Ecology 79: 28282838.

Hmeljevski K, Wolowski M, Forzza R, Freitas L. 2017. High outcrossing rates and short-distance pollination in a species restricted to granitic inselbergs. Australian Journal of Botany 65: 315-326.

Hodges SA. 1993. Consistent interplant variation in nectar characteristics of Mirabilis multiflora. Ecology 74: 542-548.

Hoehn P, Tscharntke T, Tylianakis, JM, Steffan-Dewenter I. 2008. Functional group diversity of bee pollinators increases crop yield. Proceedings of the Royal Society B 275: 2283-2291.

Javorek SK, Mackenzie KE, Vander Kloet SP. 2002. Comparative pollination effectiveness among bees (Hymenoptera: Apoidea) on Lowbush Blueberry (Ericaceae: Vaccinium angustifolium). Annals of the Entomological Society of America 95: 345-351.

Kaehler M, Varassin IG, Goldenberg R. 2005. Polinização em uma comunidade de bromélias em floresta atlântica alto-montana no estado do Paraná, Brasil. Brazilian Journal of Botany 28: 219-228.

Kamke R, Schmid S, Zillikens A, Cortés-Lopes B, Steiner J. 2011. The importance of bees as pollinators in the short corolla bromeliad Aechmea caudata in Southern Brazil. Flora 206: 749-756.

Kearns CA, Inouye DW. 1993. Techniques for pollination biologists. Niwot, USA, University of Colorado Press.

Kennedy BF, Elle E. 2008. The reproductive assurance benefit of selfing: importance of flower size and population size. Oecologia 155: 469477.

Kessler M, Abrahamczyk S, Krömer T. 2020. The role of hummingbirds in the evolution and diversification of Bromeliaceae: unsupported claims and untested hypotheses. Botanical Journal of the Linnean Society 192: 592-608.

Kessler M, Krömer T. 2000. Patterns and ecological correlates of pollination modes among bromeliad communities of Andean forests in Bolivia. Plant Biology 2: 659-669.

King C, Ballantyne G, Willmer PG. 2013. Why flower visitation is a poor proxy for pollination: measuring single-visit pollen deposition, with implications for pollination networks and conservation. Methods in Ecology and Evolution 4: 811-818.

Krömer T, Acebey A, Kluge J, Kessler M. 2013. Effects of altitude and climate in determining elevational plant species richness patterns: a case study from Los Tuxtlas, Mexico. Flora 208: 197-210.

Krömer T, Espejo-Serna A, López-Ferrari AR, Ehlers R, Lautner J. 2012. Taxonomic and nomenclatural status of the Mexican species in the Tillandsia viridiflora complex (Bromeliaceae). Acta Botánica Mexicana 99: 1-20.

Krömer T, Kessler M, Herzog SK. 2006. Distribution and flowering ecology of bromeliads along two climatically contrasting elevational transects in the Bolivian Andes. Biotropica 38: 183-195.

Krömer T, Kessler M, Lohaus G, Schmidt-Lebuhn AN. 2008. Nectar sugar composition and concentration in relation to pollination syndromes in Bromeliaceae. Plant Biology 10: 502-511.

Lara C, Ornelas JF. 2002. Flower mites and nectar production in six hummingbird-pollinated plants with contrasting flower longevities. Canadian Journal of Botany 80: 1216-1229.

Larson BMH, Barret SCH. 2000. A comparative analysis of pollen limitation on flowering plants. Biological Journal of the Linnean Society 69: 503-520.
Leal RLB, Moreira MM, Pinto AR, Ferreira JO, Rodriguez-Girones M, Freitas L. 2020. Temporal changes in the most effective pollinator of a bromeliad pollinated by bees and hummingbirds. PeerJ 8: e8836. doi: $10.7717 /$ peerj.8836

Lloyd DG. 1965. Evolution of self-compatibility and racial differentiation in Leavenworthia (Cruciferae). Contributions from the Gray Herbarium of Harvard University 195: 3-134.

Lloyd DG. 1992. Self- and cross-fertilization in plants. II. The selection of self- fertilization. Indian Journal of Pharmaceutical Sciences 153: 370-380.

Lobo J, Solís S, Fuchs EJ, Quesada M. 2012. Individual and temporal variation in outcrossing rates and pollen flow patterns in Ceiba pentandra (Malvaceae: Bombacoidea). Biotropica 45: 185-194.

Lobo JA, Quesada M, Stoner KE, Fuchs EJ, Herrerías-Diego Y, Rojas J, Saborío G. 2003. Factors affecting phenological patterns of bombacaceous trees in seasonal forests in Costa Rica and Mexico. American Journal Botany 90: 1054-1063.

Marques JT, Ramos-Pereira MJ, Marques TA, et al. 2013. Optimizing sampling design to deal with mist-net avoidance in Amazonian birds and bats. PLOS ONE 8: e74505. doi: 10.1371/journal.pone.0074505

Martén-Rodríguez S, Fenster CB. 2008. Pollination ecology and breeding systems of five Gesneria species from Puerto Rico. Annals of Botany 102: 23-30.

Martinelli G. 1994. Reproductive biology of Bromeliaceae in the Atlantic rainforest of southeastern Brazil. PhD Thesis. University of Saint Andrews, Saint Andrews.

Medellín AR, Arita TH, Sánchez O. 2008. Identificación de los murciélagos de México, clave de campo. México D.F., Mexico, Instituto de EcologíaUNAM.

Montalvo AM, Ackerman JD. 1986. Relative pollinator effectiveness and evolution of floral traits in Spathiphyllum friedrichsthalii (Araceae). American Journal of Botany 73: 1665-1676.

Morrison D. 1978. Lunar phobia in a Neotropical bat, Artibeus jamaicensis (Chiroptera: Phyllostomidae). Animal Behaviour 26: 852-855.

Muchhala N, Jarrín-V P. 2002. Flower visitation by bats in cloud forests of Western Ecuador. Biotropica 34: 387-395.

Muchhala N, Thomson JD. 2010. Fur versus feathers: pollen delivery by bats and hummingbirds and consequences for pollen production. American Naturalist 175: 717-726.

Muchhala N, Thomson JD. 2012. Interspecific competition in pollination systems: costs to male fitness via pollen misplacement. Functional Ecology 26: 476-482.

Muchhala N. 2006. The pollination biology of Burmeistera (Campanulaceae): specialization and syndromes. American Journal of Botanical 93: 1081-1089.

Müller N, Schneller JJ, Holderegger R. 2000. Variation in breeding system among populations of the common woodland herb Anemone nemorosa (Ranunculaceae). Plant Systematics and Evolution 221: 69-76.

Munguía-Rosas MA, Sosa VJ, Jácome-Flores ME. 2010. Pollination system of Pilosocereus leucocephalus columnar cactus (tribe Cereeae) in Eastern Mexico. Plant Biology 12: 578-586.

Muñiz-Castro MA, Williams-Linera G, Rey Benayas JM. 2006. Distance effect from cloud forest fragments on plant community structure in abandoned pastures in Veracruz, Mexico. Journal of Tropical Ecology 22: $431-440$

Nassar JM, Ramírez N, Linares O. 1997. Comparative pollination biology of Venezuelan columnar cacti and the role of nectarfeeding bats in their sexual reproduction. American Journal of Botany 84: 918-927.

Ne'eman G, Jurgens A, Newstrom-Lloyd L, Potts SG, Dafni A. 2010. A framework for comparing pollinator performance: effectiveness and efficiency. Biological Reviews 85: 435-451.

Newman E, Manning J, Anderson B. 2014. Matching floral and pollinator traits through guild convergence and pollinator ecotype formation. Annals of Botany 113: 373-384.

Noe S, Manley-Harris M, Clearwater MJ. 2019. Floral nectar of wild mānuka (Leptospermum scoparium) varies more among plants than among sites. New Zealand Journal of Crop and Horticultural Science 47: 282-296. 


\section{Pedro Adrián Aguilar-Rodríguez, Marco Tschapka, José G. García-Franco, Thorsten Krömer, Juan Carlos López-Acosta and M. Cristina MacSwiney G.}

Ollerton J, Dafni A. 2005. Functional floral morphology and phenology. In: Dafni A, Kevan PG, Husband BC. (eds.) Practical Pollination Biology. Ontario, Canada, Enviroquest Ltd Cambridge. p. 1-26.

Ordano M, Ornelas JF. 2004. Generous-like flowers: nectar production in two epiphytic bromeliads and a meta-analysis of removal effects. Oecologia 140: 495-505.

Paggi GMM, Palma-Silva C, Bodanese-Zanettini MH, Lexer C, Bered F. 2015. Limited pollen flow and high selfing rates toward geographic range limit in an Atlantic forest bromeliad. Flora 211: 1-10.

Parachnowitsch AL, Manson JS, Sletvold N. 2019. Evolutionary ecology of nectar. Annals of Botany 123: 247-261.

Pérez-Barrales R, Arroyo J, Armbruster SW. 2007. Differences in pollinator faunas may generate geographic differences in floral morphology and integration in Narcissus papyraceus (Amaryllidaceae). Oikos 116: 1904-1918.

Quesada M, Stoner KE, Lobo JA, et al. 2004. Effects of forest fragmentation on pollinator activity and consequences for plant reproductive success and mating patterns in bat-pollinated Bombacaceous trees. Biotropica 36: 131-138.

Quesada M, Stoner KE, Lobo JA, et al. 2006. Effects of forest fragmentation on pollinator activity and consequences for plant reproductive success and mating patterns in bat-pollinated Bombacaceous trees. Biotropica 36: $131-138$

Quesada M, Stoner KE, Rosas-Guerrero V, Palacios-Guevara C, Lobo JA. 2003. Effects of habitat disruption on the activity of nectarivorous bats (Chiroptera: Phyllostomidae) in a dry tropical forest: implications for the reproductive success of the Neotropical tree Ceiba grandiflora. Oecologia 135: 400-406.

R Development Core Team. 2012. R: A language and environment for statistical computing. R Foundation for Statistical Computing, Vienna, Austria. https://www.r-project.org/. 4 Jul. 2020.

Raduski AR, Haney EB, Igić B. 2012. The expression of self-incompatibility in angiosperms is bimodal. Evolution 66: 1275-1283.

Reid F. 2009. A field guide to the mammals of Central America and Southeast Mexico. Oxford, UK, Oxford University Press.

Rocca MA, Sazima M. 2013. Quantity versus quality: identifying the most effective pollinators of the hummingbird-pollinated Vriesea rodigasiana (Bromeliaceae). Plant Systematics and Evolution 299: 97-105.

Rogers SR, Tarpy DR, Burrack HJ. 2013. Multiple criteria for evaluating pollinator performance in highbush blueberry (Ericales: Ericaceae) agroecosystems. Environmental Entomology 42: 1201-1209.

Rovere AE, Smith-Ramírez C, Armesto JJ, Premoli AC. 2006. Breeding system of Embothrium coccineum (Proteaceae) in two populations on different slopes of the Andes. Revista Chilena de Historia Natural 79: 225-232.

Ryniewicz J, Skłodowski M, Chmur M, et al. 2020. Intraspecific variation in nectar chemistry and its implications for insect visitors: The case of the medicinal plant, Polemonium caeruleum L. Plants 9: 1297. doi: 10.3390/plants9101297

Saldaña-Vazquez RA, Ortega J, Guerrero JA, et al. 2020. Ambient temperature drives sex ratio and presence of pregnant females of Anoura geoffroyi (Phyllostomidae) bats living in temperate forests. Journal of Mammalogy 101: 234-240.

Sánchez-Casas N, Álvarez T. 2000. Palinofagia de los murciélagos del genero Glossophaga (Mammalia: Chiroptera) en México. Acta Zoológica Mexicana 81: 23-62.

Santos-Moreno A, Velásquez-Ruíz E, Sánchez-Martínez A. 2010. Efecto de la intensidad de la luz lunar y de la velocidad del viento en la actividad de murciélagos filostómidos de Mena Nizanda, Oaxaca, México. Revista Mexicana de Biodiversidad 81: 839-845.

Sazima M, Buzato S, Sazima I. 1999. Bat-pollinated flower assemblage and bat visitors at two Atlantic forest sites in Brazil. Annals of Botany 83: 705-712.

Schlumpberger BO, Cocucci AA, Moré M, Sérsic AN, Raguso RA. 2009. Extreme variation in floral characters and its consequences for pollinator attraction among populations of an Andean cactus. Annals of Botany 103: 1489-1500.

Schmid S, Schmid VS, Zillikens A, Harter-Marques B, Steiner J. 2011a. Bimodal pollination system of the bromeliad Aechmea nudicaulis involving hummingbirds and bees. Plant Biology 13: 41-50.
Schmid S, Schmid VS, Zillikens A, Steiner J. 2011b. Diversity of flower visitors and their role for pollination in the ornithophilous bromeliad Vriesea friburgensis in two different habitats in southern Brazil. Ecotropica 17: 91-102.

Silva VJD, Ribeiro EM, Luizi-Ponzo AP, Faria APG. 2016. Ultrastructure and pollen morphology of Bromeliaceae species from the Atlantic rainforest in southeastern Brazil. Anais da Academia Brasileira de Ciências 88: 439-449.

Simmons NB. 2005. Order Chiroptera. In: Wilson DE, Reeder DM. (eds.) Mammal species of the world. A taxonomic and geographic reference. 3rd. edn. Baltimore, USA, Johns Hopkins University Press. p. 312-529.

Solís-Montero L, Vallejo-Marín M. 2017. Does the morphological fit between flowers and pollinators affect pollen deposition? An experimental test in a buzz-pollinated species with anther dimorphism. Ecology and Evolution 7: 2706-2715.

Sosa VJ, Hernández-Salazar E, Hernández-Conrique D, Castro-Luna AA. 2008. Murciélagos. In: Manson RH, Hernández-Ortíz V, Gallina S, Mehltreter K. (eds.) Agroecosistemas cafetaleros de Veracruz biodiversidad, manejo y conservación. Xalapa, Mexico, Instituto de Ecología A.C. - INECOL, Instituto Nacional de Ecología - INESEMARNAT. p. 181-192.

Soto M. 2004. El clima. In: Guevara S, Laborde DJ, Sánchez-Ríos G. (eds.) Los Tuxtlas. El paisaje de la sierra. Xalapa, Mexico, Instituto de Ecología, A. C. \& European Union. p. 195-199.

Southwick EE. 1984. Photosynthate allocation to floral nectar: a neglected energy investment. Ecology 6: 1775-1779.

Souza EH, Souza FVD, Rossi ML, Packer RM, Cruz-Barros MAV, Martinelli AP. 2017. Pollen morphology and viability in Bromeliaceae. Anais da Academia Brasileira de Ciências 89: 3067-3082.

Sperr EB, Caballero-Martínez LA, Medellín RA, Tschapka M. 2011. Seasonal changes in species composition, resource use and reproductive patterns within a guild of nectar-feeding bats in a west Mexican dry forest. Journal of Tropical Ecology 27: 133-145.

Stahl JM, Nepi M, Galetto L, Guimarães E, Rodrigues Machado S. 2012. Functional aspects of floral nectar secretion of Ananas ananassoides, an ornithophilous bromeliad from the Brazilian savanna. Annals of Botany 109: 1243-1252.

Stewart A, Dudash MR. 2016. Differential pollen placement on an Old World nectar bat increases pollination efficiency. Annals of Botany 117: 145-152.

Stewart AB, Dudash MR. 2017a. Field evidence of strong differential pollen placement by Old World bat-pollinated plants. Annals of Botany 119: 73-79.

Stewart AB, Dudash MR. 2017b Flower-visiting bat species contribute unequally toward agricultural pollination ecosystem services in southern Thailand. Biotropica 49: 239-248.

Straube FC, Bianconi GV. 2002. Sobre a grandeza e a unidade utilizada para estimar esforço de captura com utilização de redes-de-neblina. Chiroptera Neotropical 8: 1-2

Thompson JN. 1994. The coevolutionary process. Chicago, USA, The University of Chicago Press.

Toledo-Aceves T, García-Franco J, Williams-Linera G, MacMillan K, Gallardo C. 2014. Significance of remnant cloud forest fragments as reservoirs of tree and epiphytic bromeliad diversity. Tropical Conservation Science 7: 230-243.

Tschapka M, von Helversen O. 2007. Phenology, nectar production and visitation behaviour of bats on the flowers of the bromeliad Werauhia gladioliflora in Costa Rican lowland rain forest. Journal of Tropical Ecology 23: 385-395.

Tschapka M. 2003. Pollination of the understorey palm Calyptrogyne ghiesbreghtiana by hovering and perching bats. Biological Journal of the Linnean Society 80: 281-288.

Valverde J, Perfectti F, Gómez JM. 2019. Pollination effectiveness in a generalist plant: adding the genetic component. New Phytologist 223: 354-365.

Voigt CC, Kelmy DH, Bradley BJ, Ortmann S. 2009. Dietary analysis of plant-visiting bats. In: Kunz TH, Parsons S. (eds.) Ecological and behavioral methods for the study of bats. Baltimore, USA, The John Hopkins University Press. p. 593-609. 
Voigt CC. 2004. The power requirements (Glossophaginae: Phyllostomidae) in nectar-feeding bats for clinging to flowers. Journal of Comparative Physiology B 174: 541-548.

von Helversen O, Reyer HU. 1984. Nectar intake and energy expenditure in a flower visiting bat. Oecologia 63: 178-184.

von Helversen O, Winter Y. 2003 Glossophagine bats and their flowers: costs and benefits for plants and pollinators. In: Kunz TH, Fenton MB. (eds.) Ecology of bats. Chicago, USA, The University of Chicago Press. p. 346-398

Wang H, Cao GX, Wang LL, Yang YP, Zhang ZQ, Duan YW. 2017. Evaluation of pollinator effectiveness based on pollen deposition and seed production in a gynodieocious alpine plant, Cyananthus delavayi. Ecology and Evolution 7: 8156-8160.

Watts S, Huamán OD, Moreno HM, Ollerton J. 2011. Pollinator effectiveness of native and non-native flower visitors to an apparently generalist Andean shrub, Duranta mandonii (Verbenaceae). Plant Species Biology 27: 147-158

Wendt T, Ferreira CMB, Gelli de Faria AP, Iglesias-Rios R. 2001. Reproductive biology and natural hybridization between two endemic species of Pitcairnia (Bromeliaceae). American Journal of Botany 88: 1760-1767.

Wendt T, Ferreira CMB, Gelli de Faria AP, Iglesias-Rios R. 2002. Selfing facilitates reproductive isolation among three sympatric species of Pitcairnia (Bromeliaceae). Plant Systematics and Evolution 232: 201-212.
Whitehead MR, Lanfear R, Mitchell RJ, Karron JD. 2018. Plant mating systems often vary widely among populations. Frontiers in Ecology and Evolution 6: 38. doi: 10.3389/fevo.2018.00038

Willcox BK, Aizen MA, Cunningham SA, Mayfield MM, Rader R. 2017. Deconstructing pollinator community effectiveness. Current Opinion in Insect Science 21: 98-104.

Willmer P. 2011. Pollination and floral ecology. Princeton \& Oxford, UK, Princeton University Press.

Wilson DE, Cole FR, Nichols JD, Rudran R, Foster MS. 1996. Measuring and monitoring biological diversity. Standard methods for mammals. Washington D. C., USA, Smithsonian Institution Press.

Wyatt R, Broyles SB, Derda GS. 1992. Environmental influences on nectar production in milkweeds (Asclepias syriaca and A. exaltata). American Journal of Botany 79: 636-642.

Zamora P, Castillo-Campos G. 1997. Vegetación y flora del municipio de Tlalnelhuayocan, Veracruz. Xalapa, Mexico, Universidad Veracruzana.

Zapata TR, Arroyo MTK. 1978. Plant reproductive ecology of a secondary deciduous tropical forest in Venezuela. Biotropica 10: 221-230.

Zotz G. 2013. The systematic distribution of vascular epiphytes - a critical update. Botanical Journal of the Linnean Society 171: 453-481.

Zywiec M, Delibes M, Fedriani JM. 2012. Microgeographical, interindividual, and intra-individual variation in the flower characters of Iberian pear Pyrus bourgaeana (Rosaceae). Oecologia 169: 713-722. 